\title{
Underwater floating robot-fish: a comparative analysis of the results of mathematical modelling and full-scale tests of the prototype
}

\author{
Sergey Jatsun*, Boris Lushnikov, Evgeny Politov and Sergey Knyazev \\ SouthWest State University, Department of Mechanics, Mechatronics and robotics, 305040 94, 50 let Oktyabrya, Kursk, Russia
}

\begin{abstract}
The article presents a comparative analysis of the results of computer mathematical modelling of the motion of the underwater robot-fish implemented by using the MATLAB / Simulink package and fullscale tests of an experimental model developed in the laboratory of mechatronics and robotics of the SouthWest State University.
\end{abstract}

\section{Introduction}

At present, unmanned autonomous underwater vehicles (AUV) that possess high autonomy, modern sensory and navigational equipment and intelligent control have become the main robotic mobile device for solving various tasks of human activity in the hydrosphere of the ocean [1-11]. The main leaders in the field of autonomous underwater vehicles are the United States, China and the United Kingdom. They produce about $50 \%$ of the total number of underwater robots, and also have about the same relative volume of scientific publications on this topic. An even more significant predominance of these countries is the financing of research and development work related to various aspects of underwater robotics.

The main tasks of such devices are: monitoring the hydrosphere and the technical condition of underwater man-made objects, exploration of underwater resources, conducting survey, search and rescue operations, as well as military reconnaissance operations that make high demands on the noiselessness and secrecy of the underwater robot.

Papers [12-20] considers the new principles of motion of mobile robots interacting with the water environment, as well as the development of underwater vehicles of various types and the principle of motion, including bionic.

In this paper, we present a comparative analysis of the results of computer mathematical modelling of the movement of an underwater floating robot-fish in the MATLAB / Simulink and full-scale prototype tests.

\section{Design and principle of action of the robot-fish prototype}

A three-dimensional model of the developed design of the bionic robot is shown in Figure 1. The main structural elements of it are the body, peduncle 6, caudal fin 7 and lateral fins (in Figure 1 - not shown). In the body of the robot we have: a system of static immersion and ascent of the robot 1 with drive 2; video camera 3; rechargeable battery 4; drive of the fin control system 5; drive of the precursor control system 8 and the lighting, navigation and autonomous control subsystems (not shown in Figure 1). In the body of the antechamber there is a drive 8 of the caudal fin 7 .

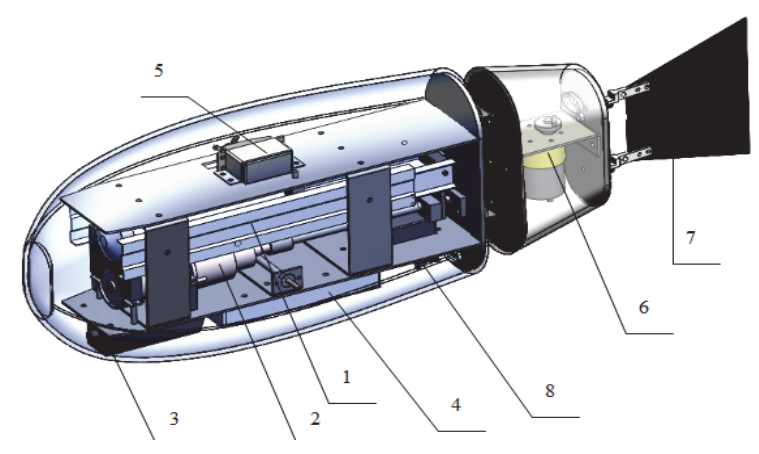

Fig.1. The three-dimensional model of the developed design of the bionic robot: 1 - the robot immersion system; 2 - the drive of the immersion system; 3 - video camera; 4 - the storage battery; 5 - drive of the fin control system; 6 - tail control system drive; 7 - tail; 8 - drive of the control system.

The general view of the prototype of the robot fish is shown in Figure 2. The forward rectilinear movement of the robot occurs due to the oscillating motion of the caudal fin, while turning in the horizontal plane - due to rotation of the forecourt relative to the robot body. Vertical diving or ascent is implemented by regulating Archimedes force with the help of intake or displacement of seawater. The regime of dynamic immersion or ascent is possible by changing the angle of inclination of the lateral fins with simultaneous operation of the caudal fin. If the premounting is included in the

\footnotetext{
* Corresponding author: teormeh@inbox.ru
} 
work, then the robot can move along a complex spatial trajectory.

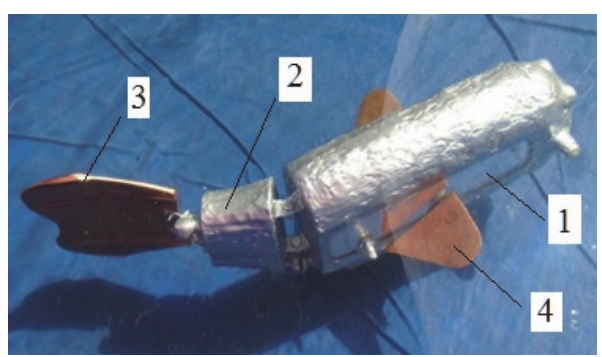

Fig. 2. General view of the prototype of the robot-fish during the tests in the shallow basin: 1 - body, 2 - peduncle, 3 - caudal fin, 4 - lateral fins.

The main technical characteristics of the developed prototype of the robot with a bionic principle of motion are presented in Table 1.

Table 1. The main technical characteristics of the robot fish.

\begin{tabular}{|l|l|l|}
\hline № & Characteristic & Value \\
\hline 1. & $\begin{array}{l}\text { Dimensions } \\
\text { (length } \times \text { height } \times \text { width), m }\end{array}$ & $\begin{array}{l}0.70 \times 0.23 \\
\times 0.28\end{array}$ \\
\hline 2. & Displacement, kg & 5.9 \\
\hline 3. & Payload, kg & 1.8 \\
\hline 4. & Battery capacity, mA/hour & 3500 \\
\hline 5. & Maximum speed underwater, m/s & 0.42 \\
\hline 6. & $\begin{array}{l}\text { Maximum vertical diving } \\
\text { (ascent) speed, m/s }\end{array}$ & 0.08 \\
\hline 7. & $\begin{array}{l}\text { Maneuverability (minimum } \\
\text { turning radius), m }\end{array}$ & 0.45 \\
\hline 8. & $\begin{array}{l}\text { Swing angle of the caudal fin, } \\
\text { degrees }\end{array}$ & $-30 \ldots 30$ \\
\hline 9. & $\begin{array}{l}\text { Turning angle of peduncle, } \\
\text { degrees }\end{array}$ & $-25 \ldots 25$ \\
\hline 10. & $\begin{array}{l}\text { Angle of rotation of the lateral } \\
\text { fins, degrees }\end{array}$ & $-30 \ldots 30$ \\
\hline 11. & $\begin{array}{l}\text { Frequency of oscillations of the } \\
\text { caudal fin, Hz }\end{array}$ & $0 \ldots 8$ \\
\hline 12. & $\begin{array}{l}\text { Power consumption at maximum } \\
\text { speeds, W }\end{array}$ & 55 \\
\hline
\end{tabular}

The operating principle of the underwater robot control system is described in [16].

\section{Mathematical model of robot-fish}

During the design stage, a mathematical model of the robot-fish was developed to determine and study the basic laws of motion, the choice of optimal design parameters according to the quality criteria, which determines the minimum power consumption, maximum speed, maneuverability and other characteristics.

A three-link kinematic scheme shown in Figure 3 was adopted as an analytical model of the mathematical model of motion of a bionic floating robot in the horizontal plane.

The system of algebraic differential equations describing the dynamics of the system under consideration will have the following form:

$$
\left\{\begin{array}{c}
\mathrm{m}_{\mathrm{tX}} \ddot{\mathrm{X}}=\mathrm{F}_{\mathrm{TX}}\left(\mathrm{X}, \mathrm{Y}, \theta, \Psi_{1}, \Psi_{2}, \mathrm{t}\right)+\mathrm{F}_{\text {sopr }}(\dot{\mathrm{X}}) ; \\
\mathrm{m}_{\mathrm{t} Y} \ddot{\mathrm{Y}}=\mathrm{F}_{\mathrm{TY}}\left(\mathrm{X}, \mathrm{Y}, \theta, \Psi_{1}, \Psi_{2}, \mathrm{t}\right)+\mathrm{F}_{\text {sopr }}(\dot{\mathrm{Y}}) ; \\
\mathrm{I}_{\theta} \ddot{\theta}=\mathrm{M}_{\mathrm{C}}\left(\mathrm{F}_{\mathrm{t}}\right)+\mathrm{M}_{\text {sopr }}(\dot{\theta})+\mathrm{M}_{\mathrm{t}}\left(\dot{\mathrm{X}}, \dot{\mathrm{Y}}, \theta, \Psi_{1}, \Psi_{2}\right) \\
\Psi_{1}(\mathrm{t})=\pi+\theta(\mathrm{t})+\theta_{1}(\mathrm{t}) ; \\
\Psi_{2}(\mathrm{t})=\Psi_{1}(\mathrm{t})+\theta_{2}(\mathrm{t}) .
\end{array}\right.
$$

Using the provisions of the aerodynamic theory of the wing, the lifting (traction) force acting on the moving flat plate can be determined according to the following expression [7]:

$$
\overline{\mathrm{F}_{\mathrm{T}}}=\pi \rho S\left(\overline{\mathrm{v}_{\mathrm{q}}} \times \overline{\mathrm{l}_{\mathrm{B}}}\right) \times \overline{\mathrm{v}_{\mathrm{q}}},
$$

where $\rho$ is the density of the medium (water); $\mathrm{S}$ is the surface area of the plate; $\vec{v}_{q}$ - velocity vector of the point of the plate, located at a distance of a quarter of its length from the axis of rotation; $\vec{l}_{e}$ - a unit vector located in the plane of the plate and determined by the coordinates:

$$
\mathrm{l}_{\mathrm{e}}=\left[\begin{array}{lll}
-\cos \left(\psi_{2}\right), & -\sin \left(\psi_{2}\right), \quad 0
\end{array}\right]
$$

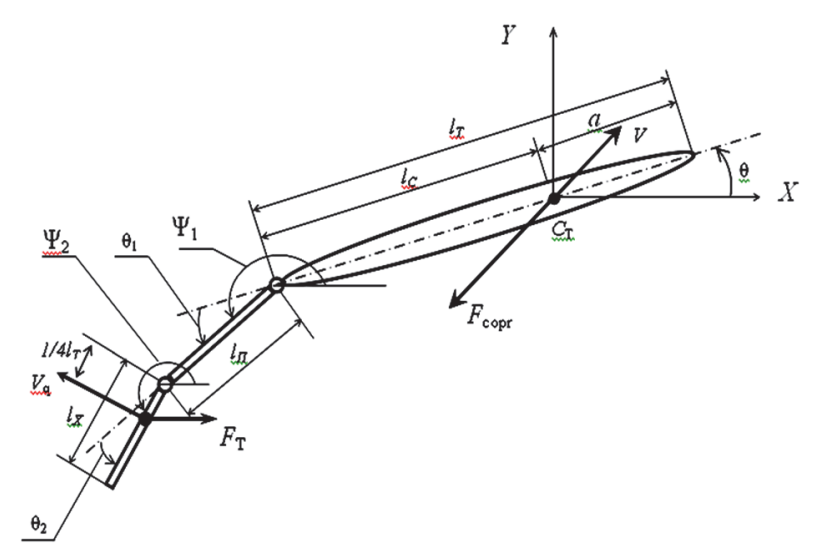

Fig. 3. Analytical diagram of the bionic floating robot in the horizontal plane: $\mathrm{X}-\mathrm{Y}$ - rectangular inertial coordinate system; $l$ - length of the "body" of the robot; $l_{\Pi}$ is the length of the caudal peduncle; $l_{\mathrm{T}}$ is the length of the caudal fin; $\mathrm{C}_{\mathrm{T}}$ is the point corresponding to the center of mass of the "body" of the robot; $\mathrm{V}$ is the vector of the absolute velocity of the center of mass; $F_{\text {copr }}$ is the vector of the drag force of the robot body. $V_{q}$ is the linear velocity vector of the point of the caudal fin at a distance equal to $1 / 4$ of its length from the axis of rotation; $\theta$ - angular coordinate of the central longitudinal axis line of the robot body; $\theta_{1}$ and $\theta_{2}$ are the relative rotation angles of the leading and tail fins respectively around their rotation axes; $\psi_{1}$ and $\psi_{2}$ are the absolute angular coordinates of the position of the caudal peduncle and caudal fin, respectively; FT - the vector of the traction force, which arises when rotational motion of the caudal fin.

The coordinates of the speed vector $\overrightarrow{v_{q}}$ are determined by the following expressions:

$$
\begin{gathered}
\mathrm{V}_{\mathrm{qX}}(\mathrm{t})=\mathrm{V}_{\mathrm{X}}+\mathrm{L}_{\text {copt }} \cdot \sin (\theta(\mathrm{t})) \cdot \mathrm{d} \theta(\mathrm{t})- \\
-\mathrm{L}_{\mathrm{P}} \cdot \sin \left(\Psi_{1}(\mathrm{t})\right) \cdot \mathrm{d} \Psi_{1}(\mathrm{t})-\frac{\mathrm{L}_{\mathrm{t}}}{4} \sin \left(\Psi_{2}(\mathrm{t})\right) \cdot \mathrm{d} \Psi_{2}(\mathrm{t}) ; \\
\mathrm{V}_{\mathrm{qY}}(\mathrm{t})=\mathrm{V}_{\mathrm{Y}}-\mathrm{L}_{\mathrm{copt}} \cdot \cos (\theta(\mathrm{t})) \cdot \mathrm{d} \theta(\mathrm{t})+
\end{gathered}
$$




$$
\begin{gathered}
+\mathrm{L}_{\mathrm{P}} \cdot \cos \left(\Psi_{1}(\mathrm{t})\right) \cdot \mathrm{d} \Psi_{1}(\mathrm{t})+\frac{\mathrm{L}_{\mathrm{t}}}{4} \sin \left(\Psi_{2}(\mathrm{t})\right) \cdot \mathrm{d} \Psi_{2}(\mathrm{t}) \\
\mathrm{V}_{\mathrm{qZ}}(\mathrm{t})=0
\end{gathered}
$$

Then the projections of the vector $\mathrm{F}_{\mathrm{T}}$ on the $\mathrm{X}$ and $\mathrm{Y}$ axis have the form:

$$
\begin{aligned}
& \mathrm{F}_{\mathrm{TX}}(\mathrm{t})=\pi \rho \mathrm{S}\left(\mathrm{V}_{\mathrm{qX}}(\mathrm{t}) \cdot \sin \left(\Psi_{2}(\mathrm{t})\right)-\mathrm{V}_{\mathrm{qY}}(\mathrm{t}) \cdot\right. \\
& \left.\cos \left(\Psi_{2}(\mathrm{t})\right)\right) \cdot \mathrm{V}_{\mathrm{qY}}(\mathrm{t}) ; \\
& \mathrm{F}_{\mathrm{TY}}(\mathrm{t})=\pi \rho S\left(-\mathrm{V}_{\mathrm{qX}}(\mathrm{t}) \cdot \sin \left(\Psi_{2}(\mathrm{t})\right)+\mathrm{V}_{\mathrm{qY}}(\mathrm{t}) \cdot\right. \\
& \left.\cos \left(\Psi_{2}(\mathrm{t})\right)\right) \cdot \mathrm{V}_{\mathrm{qX}}(\mathrm{t}) .
\end{aligned}
$$

Besides thrust a torque, given by the expression below, also acts on the tail plate:

$$
\begin{aligned}
& \mathrm{M}_{\mathrm{t}}=-\pi \rho \frac{\mathrm{L}_{\mathrm{t}}^{2}}{4}\left(\dot{\mathrm{x}}_{\mathrm{m}} \dot{\mathrm{y}}_{\mathrm{m}} \cos \left(2 \Psi_{2}(\mathrm{t})\right)+\right. \\
& \left.\frac{1}{2}\left(\dot{\mathrm{y}}_{\mathrm{m}}^{2}-\mathrm{x}_{\mathrm{m}}^{2}\right)\right) \sin \left(2 \Psi_{2}(\mathrm{t})\right),
\end{aligned}
$$

where $\dot{x}_{m}, \dot{y}_{m}-$ projection of the velocity vector of the midpoint of the tail plate on the $\mathrm{X}$ and $\mathrm{Y}$ axes.

The body of the robot-fish will also be acted upon by the torque vector of the thrust force, the drag force of the fluid and the viscous drag moment. To determine the last two factors, it is necessary to integrate the forces distributed over the surface of the robot-fish body. For preliminary calculations, we will consider these force factors to be proportional to the corresponding velocities:

$$
\begin{aligned}
& \mathrm{F}_{\text {soprX }}=\mu_{\mathrm{X}} \mathrm{V}_{\mathrm{X}} \\
& \mathrm{F}_{\text {sopry }}=\mu_{\mathrm{Y}} \mathrm{V}_{\mathrm{Y}} ; \\
& \mathrm{M}_{\text {sopr }}=\mu_{\theta} \dot{\theta} .
\end{aligned}
$$

The moment of the traction force acting on the body of the robot relative to its center of mass is determined in accordance with the vector product:

$$
\mathrm{M}_{\mathrm{C}}\left(\mathrm{F}_{\mathrm{T}}\right)=\left[\mathrm{X}_{\mathrm{Cq}}, \mathrm{Y}_{\mathrm{Cq}}\right] \times\left[\mathrm{F}_{\mathrm{TX}}, \mathrm{F}_{\mathrm{TY}}\right] \text {, }
$$

where $\mathrm{X}_{\mathrm{Cq}}, \mathrm{Y}_{\mathrm{Cq}}-$ coordinates of the vector connecting the center of mass of the body of the robot-fish $\mathrm{C}_{\mathrm{T}}$ and the point of application of the traction force on the caudal fin.

As a result we obtain

$$
\mathrm{M}_{\mathrm{C}}\left(\mathrm{F}_{\mathrm{T}}\right)=\mathrm{Y}_{\mathrm{Cq}} \mathrm{F}_{\mathrm{TX}}-\mathrm{X}_{\mathrm{Cq}} \mathrm{F}_{\mathrm{TY}}
$$

For carrying out numerical studies, the mathematical model described above was implemented in the MATLAB / Simulink environment, and a comprehensive verification of its adequacy was performed [13].

In the course of computer simulation the effect of the parameters of the mathematical model of the robot-fish design on its functional and dynamic characteristics was studied.

One of the most important kinematic characteristics of a mobile robot in terms of assessing its dynamic efficiency is the swimming speed. The greatest influence on the swimming speed is exerted by the vibration frequency of the caudal fin, the mass of the robot and the area of the lateral surface of the caudal fin: the greater the frequency of oscillations and the tail area and lesser the mass of the robot, the greater the speed of its translational movement in the horizontal plane.

At the same time, it is desirable to achieve the best conditions for monitoring the environment, in particular, video and photography, measurements of physical properties of the medium, etc when the robot moving. In this regard it is therefore important to minimize the lateral displacement of the center of mass of the robot and the angular "wobble" of the body of the robot relative to the vertical axis passing through its center of gravity. In the course of numerical experiments it was found that the reduction of these two parameters is possible by increasing the frequency of tail angular vibrations and decreasing the area of the caudal fin with simultaneous elongation and an increase in mass.

As an example, Figure 4 shows graphs of the dependence of the swimming speed of the robot $\mathrm{V}$ on the frequency $f$ of the tail fin for the three amplitude values $\theta 2$ obtained as a result of mathematical modelling.

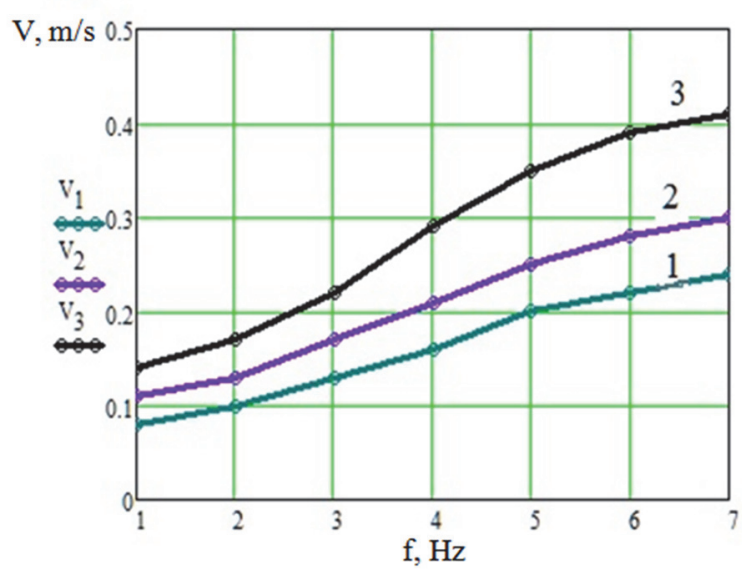

Fig. 4. The graph of the swimming speed $\mathrm{V}$ against the oscillation frequency $f$ of the tail in for three amplitude values $\theta 2$ : $1-\theta 2=10^{\circ}, 2-\theta 2=20^{\circ}$ and $\theta 2=30^{\circ}$.

From the analysis of the presented results of mathematical modelling it follows that in order to increase the efficiency of the robot (increasing speed and improving stability) it is desirable to create oscillations of the caudal fin with a sufficiently high frequency (above 3-5 Hz). However, an increase in the frequency of tail angular oscillations leads to a significant increase in the consumption of power, which obviously is a limited resource.

The size of the tail and mass of the robot adversely affect speed and lateral "wobble", and with an increase in the tail area and a decrease in body weight, the velocity decreases, but the amplitude of lateral movements increases. Therefore, in order to increase the efficiency of the robot's movement, the task of multicriteria optimization of constructive and control parameters by known methods was set and realized [12, 15]. 


\section{Comparative analysis of the results of mathematical modelling and full scale tests of the experimental prototype}

Experimental studies of the prototype fish robot were carried out in three types of reservoirs: in two types of basins (shallow water as shown in Figure 2 and deep water) and in full-scale conditions at the Kursk reservoir.

Quantitative and qualitative assessments are as follows:

- quality of functioning of lighting, video surveillance, and power supply subsystems.

- steady position of the robot during swimming and diving;

- hermeticity of the housing;

- range of controllability depending on the depth of immersion;

- range of speeds of horizontal movement in the underwater position;

- speed of dynamic immersion and ascent;

- turning radius in the horizontal plane;

- speed of static (vertical) immersion and ascent;

- depth of immersion, with which a robot can safely surface;

- performance of lighting, video surveillance, and power supply subsystems.

Figure 5 shows a graph of the average velocity $\mathrm{V}$ $(\mathrm{m} / \mathrm{s})$ of the horizontal movement of the robot in a completely submerged position against the frequency of the tail fin $\mathrm{f}(\mathrm{Hz})$ at a swing angle $\theta 2=30^{\circ}$, recorded from the results of the full-scale experiment.

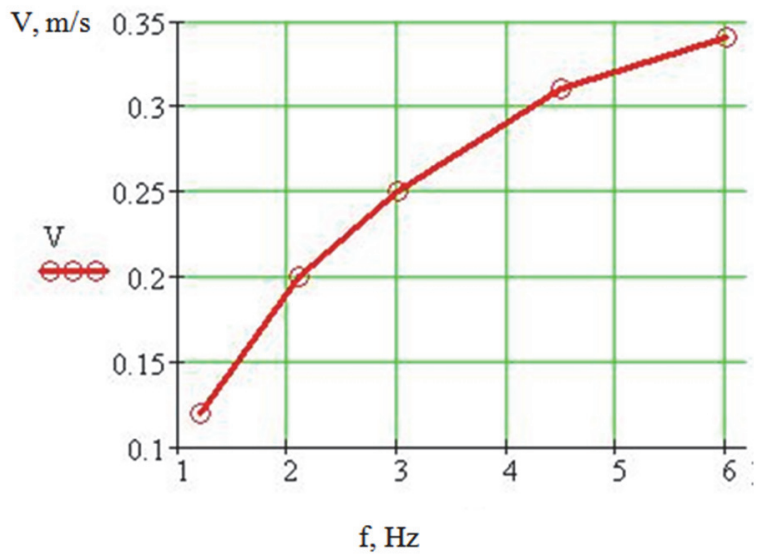

Fig. 5. Graph of the average velocity V $(\mathrm{m} / \mathrm{s})$ of the horizontal movement of the robot in a completely submerged position against the frequency of the tail fin $\mathrm{f}(\mathrm{Hz})$.

Based on the analysis of the presented graph obtained in the course of full-scale tests, we can see that the nature of the influence of the frequency of the oscillations of the caudal fin on the speed of movement of the robot is similar to that obtained in mathematical computer simulation (see Fig. 3). At the same time, an increase in the frequency $\mathrm{f}$ leads to a nonlinear increase in the average speed of the robot's motion and the shape of the graph takes the form of a "saturation" curve. This is caused by an increase in resistance to the robot's movement of the liquid with increasing speed.
Therefore, for an economical mode of the robot's motion it is necessary to use the vibration frequencies of the caudal fin in the interval from 1 to $5 \mathrm{~Hz}$, which corresponds to a speed range of 0.1 to $0.3 \mathrm{~m} / \mathrm{s}$.

The turning radius of the robot in the horizontal plane (turning radius) that characterises maneuverability is $0.45 \mathrm{~m}$, which also satisfies the requirement specification.

The rate of dynamic immersion and ascent depends on the speed of the horizontal movement of the robot and is determined by the deflection angle of the lateral fins. The maximum values of the speed of ascent (ascent) during the tests reached $0.08 \mathrm{~m} / \mathrm{s}$ with a maximum angle of attack of the lateral fins of 45 degrees.

The range of the radio control system reached $80-100$ $\mathrm{m}$ with an immersion depth of up to $1 \mathrm{~m}$ and for large immersion depths it is necessary to use a floating antenna or switch to a stand-alone program control mode. The conducted tests confirmed the results of mathematical modelling, showing that the robot's movement pattern corresponds to the calculated one since the divergence of the main characteristics does not exceed $15 \%$. The tests on the produced prototype showed that it can move in the water environment for a distance of up to $150 \mathrm{~m}$. This device makes it possible to investigate the influence of design parameters (tail area and length, frequency and amplitude of the oscillations of the tail) on the dynamic characteristics of the mobile robot, such as the speed of navigation and maneuverability.

\section{Conclusions}

The article describes the design and basic elements of an underwater floating robot device based on bionic principles of motion. The robot is able to perform both movement at a given constant depth and vertical ascent and ascent, as well as movement along a complex spatial trajectory. A mathematical model of the developed robot-fish implemented in MATLAB/Simulink for numerical computer simulation was presented.

The conducted full-scale tests of the prototype of the device of a bionic floating robot for monitoring natural and technogenic objects in the hydrosphere showed its effective operation and normal functioning of all its subsystems. The technical characteristics of the developed robot-fish fixed during the tests, basically correspond to the laid requirements and mathematical modelling. Comparative analysis of the results of computer mathematical modelling of the underwater robot-fish movement and full-scale tests of the experimental prototype showed that the discrepancy between their main characteristics does not exceed 10$15 \%$.

\section{References}

1. A.Yu. Bocharov, Underwater research and robotics, 2, 36 (2006)

2. R.J. Mason, W. Burdick, Proc. 2000 ICRA, 428 (2000) 
3. E.J. Kim, Y. Youm, Proc. 2004 IEEE Int. Conf. ICRA, 488 (2004)

4. D. Lachat, A. Crespi, A.J. Ijspeert, Proc. 1st IEEE RAS \& EMBS Int. Conf. on Biomedical Robotics and Biomechatronics, 643 (2006)

5. L. Wang, S. Wang, Z. Cao, M. Tan, C. Zhou, H. Sang, Z. Shen, Proc. IEEE International Conference on Industrial Technology, 1263 (2005)

6. J. Yuh, Autonomous Robots, 8(1), 7 (2000)

7. K.A. Morgansen, V. Duindam, R.J. Mason, J.W. Burdick, Proc. of IEEE Int. Conf. on Robotics and Automation, 427 (2001)

8. E.V. Vetchanin, Yu.L. Karavaev, A.A. Kalinkin, A.V. Klekovkin, E.N. Pivovarova, Bulletin of the Udmurt University. Mathematics. Mechanics. Computer science, 25. 4, 544 (2015)

9. L.V. Kiselev, A.V. Medvedev, Underwater research and robotics, 1 (13), 24 (2012)

10. M.D. Ageev, Autonomous underwater robots. Systems and technologies (Nauka, Moscow, 2005)

11. V.F. Filaretov, A.V. Lebedev, D.A. Yukhimets, Devices and control systems for underwater robots (Nauka, Moscow, 2005)

12. B.V. Lushnikov, S.F. Jatsun, E.N. Politov, E.S. Tarasova, Izv. Samar. Sci. Center of the Russian Academy of Sciences, 13, 4 (4), 1193 (2011)

13. B.V. Lushnikov, S.F. Jatsun, E.N. Politov, E.S. Tarasova, Izv. Samar. Sci. Center of the Russian Academy of Sciences, 12, 4 (3), 562 (2010)

14. B.V. Lushnikov, S.F. Jatsun, E.S. Tarasova, E.N. Politov, Controlled Vibration Technologies and Machines: Sat. Sci., 2, 111 (2012)

15. B.V. Lushnikov, S.I. Savin, K.G. Kazaryan, A.S. Yatsun, A.V. Malchikov, Controlled Vibration Technologies and Machines: Sat. Sci., 2,107 (2012).

16. B.V. Lushnikov, E.N. Politov, E.S. Tarasova, K.G. Kazaryan, Electronic Journal of the Cloud of Science. 1(1), 61 (2014)

17. S.F. Jatsun, B.V. Lushnikov, E.N. Politov, Proc. Perspective systems and control tasks, 208 (2016)

18. S.F. Jatsun, E.N. Politov, P.A. Bezmen, K.G. Kazaryan, Proc. Vibration technologies, mechatronics and controlled machines, 2, 277 (2016)

19. P.A. Bezmen, E.N. Politov, K.G. Kazaryan, Natural and technical sciences, 6,111 (2016)

20. B.V. Lushnikov, S.F. Jatsun, S.I. Savin, K.G. Kazaryan, A.V. Malchikov, E.S. Tarasova, E.N. Politov, A.S. Yatsun, Underwater floating robot with bionic principle of movement Russian Federation Patent 124656, Feb. 10, (2013) 